\title{
Appendicular anatomy of the artiopod Emeraldella brutoni from the middle Cambrian (Drumian) of western Utah
}

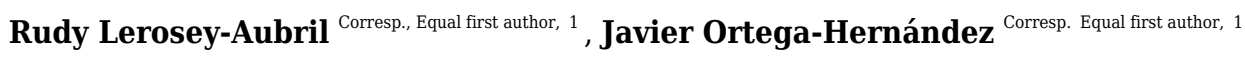 \\ ${ }^{1}$ Museum of Comparative Zoology and Department of Organismic and Evolutionary Biology, Harvard University, Cambridge, MA, United States \\ Corresponding Authors: Rudy Lerosey-Aubril, Javier Ortega-Hernández \\ Email address: rudy_lerosey@fas.harvard.edu, jortegahernandez@fas.harvard.edu
}

The non-biomineralized artiopod Emeraldella brutoni Stein, Church \& Robinson, from the middle Cambrian (Drumian) Wheeler Formation in Utah represents the only confirmed occurrence of the genus Emeraldella, outside of the stratigraphically older (Wuliuan) Burgess Shale Konservat-Lagerstätte in British Columbia. The hitherto known sole specimen of this species is preserved in dorsal view and lacks critical information on the ventral appendages. Here we redescribe $E$. brutoni based on a new completely articulated specimen that illustrates the appendage organization in exceptional detail. The main body consists of a cephalic region covered by a semicircular head shield, a trunk including 10 tergites with expanded pleurae plus a cylindrical terminal segment, and a long articulated tailspine. The head carries a pair of elongate and flexible antennae, a pair of lateral eyes, and three pairs of post-antennal appendages. We report the presence of eyes in Emeraldella for the first time. The first post-antennal limb solely consists of an endopod with well-developed paired spiniform endites. The remaining cephalic appendages and those associated with all but the last trunk segments possess exopods terminating in paddle-shaped, distal lobes fringed with robust setae. The cylindrical terminal segment bears a pair of posteriorly oriented caudal flaps reminiscent of trunk exopods, and a styliform, possibly uniarticulate tailspine longer than the main body. The new data on $E$. brutoni suggests an exopodal origin for the paired caudal structures in Vicissicaudata, and improve our understanding of the fundamental organization of this major clade within Artiopoda. 


\section{Appendicular anatomy of the artiopod Emeraldella brutoni from the}

\section{2 middle Cambrian (Drumian) of western Utah}

3

4 Rudy Lerosey-Aubril ${ }^{1}$, Javier Ortega-Hernández ${ }^{1}$

5

$6{ }^{1}$ Museum of Comparative Zoology and Department of Organismic and Evolutionary Biology,

7 Harvard University, Cambridge, MA 02138, USA.

8

9 Corresponding Authors:

10 Rudy Lerosey-Aubril

1126 Oxford Street, Cambridge, MA 02138, USA

12 Email address: rudy_lerosey@fas.harvard.edu

14 Javier Ortega-Hernández

1526 Oxford Street, Cambridge, MA 02138, USA

16 Email address: jortegahernandez@fas.harvard.edu

17

18

19

20 


\section{Abstract}

23 The non-biomineralized artiopod Emeraldella brutoni Stein, Church \& Robinson, from the middle Cambrian (Drumian) Wheeler Formation in Utah represents the only confirmed occurrence of the genus Emeraldella, outside of the stratigraphically older (Wuliuan) Burgess

Shale Konservat-Lagerstätte in British Columbia. The hitherto known sole specimen of this species is preserved in dorsal view and lacks critical information on the ventral appendages. Here we redescribe $E$. brutoni based on a new completely articulated specimen that illustrates the appendage organization in exceptional detail. The main body consists of a cephalic region covered by a semicircular head shield, a trunk including 10 tergites with expanded pleurae plus a cylindrical terminal segment, and a long articulated tailspine. The head carries a pair of elongate and flexible antennae, a pair of lateral eyes, and three pairs of post-antennal appendages. We report the presence of eyes in Emeraldella for the first time. The first post-antennal limb solely consists of an endopod with well-developed paired spiniform endites. The remaining cephalic appendages and those associated with all but the last trunk segments possess exopods terminating in paddle-shaped, distal lobes fringed with robust setae. The cylindrical terminal segment bears a pair of posteriorly oriented caudal flaps reminiscent of trunk exopods, and a styliform, possibly uniarticulate tailspine longer than the main body. The new data on E. brutoni suggests an exopodal origin for the paired caudal structures in Vicissicaudata, and improve our understanding of the fundamental organization of this major clade within Artiopoda. 


\section{Introduction}

44 The House Range and the Drum Mountains of western Utah are internationally renowned for

their richly fossiliferous Miaolingian ('middle Cambrian') strata, and particularly the beautifully preserved trilobites they contain. The abundance of trilobite fossils motivated the opening of a first quarry in the Wheeler Amphitheatre (Wheeler Formation; House Range) in the 1960s (Robison et al., 2015). Others have followed since then, including quarries in the Marjum and Weeks formations, and subsequently the area has become a major destination for trilobite collectors around the world. The exploitation of the local federal lands by fossil dealers and amateur collectors searching for trilobites led to the realization that these three Miaolingian units also contain the remains of non-biomineralizing organisms (Robison, 1991; Lerosey-Aubril et al., 2018). At least four exceptionally-preserved biotas have been described from these strata to date, including the two Wheeler biotas of the House Range and the Drum Mountains (both early Drumian), the Marjum biota (upper Drumian), and the Weeks biota (Guzhangian). Except for some early reports (e.g. Brooks \& Caster, 1956; Rigby, 1969), the scientific study of these exceptionally-preserved faunas really started in the mid-1970s and became important in the 1980s, with a series of seminal contributions by J.K. Rigby (Rigby, 1978; Rigby, 1983; Rigby \& Gutschick, 1976) and R. Robison and his collaborators (Briggs \& Robison, 1984; Conway Morris \& Robison, 1982; Conway Morris \& Robison, 1986; Conway Morris \& Robison, 1988; Robison, 1984; Robison, 1985; Robison, 1990; Robison \& Richards, 1981; Willoughby \& Robison, 1979). Most of the remarkable fossils described in these publications had been found by members of the general public, either avocational palaeontologists (e.g. the Gunther family, T. 
64 Johnson, or G. Melloy, to name a few; Gunther \& Gunther, 1981) or professional fossil

65 collectors (e.g. R. Harris). This remains true of the materials described in more recent

66 publications (e.g. Briggs et al., 2008; Conway-Morris et al., 2015; Lerosey-Aubril, 2015;

67 Lerosey-Aubril et al., 2012; Lerosey-Aubril et al., 2013a; Ortega-Hernández et al., 2015), with

68 the reason being that the soft-bodied fossils in those strata are particularly rare, especially in the

69 Wheeler and Marjum formations. Forty years after the beginning of their scientific explorations,

70 the Cambrian Konservat-Lagerstätten of western Utah are not 'minor' anymore, as once

71 described by Conway Morris (1985). These deposits have yielded between 20 to 45 soft-bodied

72 species each (Robison, Babcock \& Gunther, 2015; Lerosey-Aubril et al., 2018) and therefore

73 qualify as Tier 2 Burgess Shale-type deposits (Gaines, 2014). However, only a handful of the

74 remarkable fossils found in those beds every year end up in public institutions, and consequently

many of the non-biomineralizing taxa in the area are still officially known only from a few

(usually incomplete) specimens. Our current restudy of the Wheeler biota from the House Range

reveals that 20 of the 45 soft-bodied species it contains $(44.4 \%)$ are described in the scientific

literature based on a single fossil, and an additional nine species (another 20\%) are known from

only two or three specimens. In this context, any new soft-bodied fossils from these Konservat-

Lagerstätten hold the promise for significantly improving our understanding of these exceptional

81 Cambrian biotas. In this contribution we describe a new specimen of Emeraldella brutoni Stein,

82 Church \& Robison, 2010 (Fig. 1) [Figure 1 nearby], an artiopodan species hitherto known from

83 a single specimen found in the Wheeler strata of the Drum Mountains (Stein, Church \& Robison, 
84 2011). The new specimen is preserved in a different orientation from that of the type material,

85 providing valuable insights into the as-yet unknown appendicular anatomy of this taxon.

\section{Geological setting}

88

The four Cambrian exceptionally-preserved biotas of western Utah are found in the Miaolingian succession exposed in the House Range and the Drum Mountains, a few tens of kilometres east and north of Delta (Robison, 1991; Robison, Babcock \& Gunther, 2015; Lerosey-Aubril et al., 2018). These shale-dominated deep-water deposits are at odds with the otherwise carbonatedominated, wave-influenced sedimentological context characterizing the Miaolingian Series in the Great Desert of Utah (Miller, Evans \& Dattilo, 2012; Foster \& Gaines, 2016). This is explained by the development locally of a fault-controlled, deep-water basin during the terminal Wuliuan, which formed a prominent re-entrant into the seaward margin of the carbonate platform rimming the continent in the Early Palaeozoic (Rees, 1986; Miller, Evans \& Dattilo, 2012;

Foster \& Gaines, 2016), where fine-grained siliciclastic sediments of the outer detrital lithofacies belt were deposited. This asymmetrical trough, the so-called House Range Embayment (Rees, 1986), was subsequently filled during the Drumian to Guzhangian times by the deposits of the Wheeler, Marjum, and Weeks formations (in ascending stratigraphic order), which was accompanied by the reduction of its spatial extent. Shallow-water, carbonate platform settings were restored in the late Guzhangian (uppermost Weeks Formation). The Wheeler, Marjum, and

Weeks formations form a continuous succession of up to $600 \mathrm{~m}$ in thickness, which is dominated by calcareous mudstone with subordinate shaly to flaggy limestone (Foster \& Gaines, 2016). 

spatial extent. It mostly outcrops in the House Range and the Drum Mountains, where it has

107 yielded two clearly distinct exceptionally-preserved biotas of lower Drumian age (Ptychagnostus

108 atavus Biozone) (Robison, Babcock \& Gunther, 2015; Lerosey-Aubril \& Skabelund, 2018). The

109 new fossil of E. brutoni described here was recovered from Wheeler strata in the Drum

110 Mountains, as was the holotype and previously only known specimen of this species (Stein,

111 Church \& Robison, 2011). There, the Wheeler Formation is twice as thick (c. $300 \mathrm{~m})$ and more

112 calcareous than in the House Range (Brett et al., 2009), which is generally interpreted as

113 evidence of its more proximal position on the shelf ramp forming the eastern (now northern)

114 margin of the embayment.

\section{Material and methods}

117 The new material of E. brutoni consists of the part and counterpart of a single complete

118 individual compressed in lateral view, which is deposited in the Natural History Museum of Utah

119 (UMNH.IP.6162a and b, respectively; Fig. 2) [Figure 2 nearby]. This specimen was found by

120 B. Sisson as a loose block at a Wheeler locality well-known to fossil collectors (GPS:

$\left.12139^{\circ} 30^{\prime} 13^{\prime \prime} \mathrm{N} 112^{\circ} 59^{\prime} 23^{\prime \prime} \mathrm{W}\right)$. This site is one of the two sections that has yielded most of the soft-

122 bodied components of the Wheeler biota of the Drum Mountains ('section c' of Halgedahl et al.,

123 2009). This remarkable biota is composed of 71 species, including 30 species of non-

124 biomineralizing organisms (Robison, Babcock \& Gunther, 2015). 
125 Digital photographs were produced with a Nikon D5500 DSLR fitted with a Nikon 40mm

126 DX Micro-Nikkor lens. The specimen was photographed under direct light or cross polarized

127 illumination, either dry or immersed in water. Series of images were taken with manual focusing

128 at different focal planes, and subsequently stacked and assembled in Adobe Photoshop CS6.

129 Schematic diagrams were produced in Inkscape.

130

131 Results

132 Systematic Palaeontology

133 Phylum Euarthropoda Lankester, 1904

134 Subphylum Artiopoda Hou \& Bergström, 1997

135 Superclass Vicissicaudata Ortega-Hernández, Legg \& Braddy, 2013

136

137 Remark: We follow Lerosey-Aubril, Zhu \& Ortega-Hernández (2017a) in considering Artiopoda

138 as a subphylum, and Vicissicaudata as a superclass within it.

139

140 Genus Emeraldella Walcott, 1912

141

142 Type species: Emeraldella brocki Walcott, 1912, from the middle Cambrian (Miaolingian Series,

143 Wuliuan Stage) Burgess Shale in British Columbia (see also Bruton \& Whittington, 1983; Stein

144 \& Selden, 2012). 
146 Emended diagnosis: Artiopod with head containing one antennal and three limb-bearing post-

147 antennal segments; antennae long, exceeding 80 articles in some species; first post-antennal limb

148 consists of an endopod only, with reduced number of podomeres and well-developed spiniform

149 endites. Trunk includes 10 to 11 tergites with well-developed pleural regions, and an elongate

150 cylindrical terminal ('pre-telsonic') segment bearing a pair of ventral caudal flaps and the

151 tailspine. Proportions of endopod podomeres vary strongly along body. Endopod curving

152 outward proximally, then downward at short, knee-like, fifth podomere. Sixth podomere long,

153 distinctly stenopodous. Exopod tripartite, its proximal and middle parts articulating with basipod

154 and first podomere, respectively; proximal part bearing lamellae, while middle and distal parts

155 fringed with setae. Tailspine styliform, jointed, longer than the trunk, and lateroventrally flanked

156 by exopods modified into caudal flaps.

157

158 Remarks: We propose minor updates to the emended diagnosis of Emeraldella by Stein, Church

$159 \&$ Robison (2011) that emphasize the unique appendicular organization of this genus, as revealed

160 by UMNH.IP.6162.

161

162 Emeraldella brutoni Stein, Church \& Robinson, 2011

163 Figures 2-5

164 
165 Emended diagnosis: Species of Emeraldella with 10 trunk tergites with well-developed pleurae,

166 lateral eyes, and robust setae on exopods and caudal flaps. Emended from Stein, Church \&

167 Robison (2011).

168

169 Material, locality, horizon. The type material consists of the sole holotype KUMIP 321500 (Fig.

170 1) - the part and counterpart of a complete dorsal exoskeleton associated with a few

171 appendicular remains - which is housed in the Kansas University Museum of Natural History.

172 The fossil was collected in the Drumian strata (Ptychagnostus atavus Biozone) of the uppermost

173 part of the Wheeler Formation in the Drum Mountains, Millard County, Utah (see Stein, Church

$174 \&$ Robison, 2011, for details on the locality). The new specimen (UMNH.IP.6162; Fig. 2) comes

175 from the same strata a few tens metres to the east and is housed in the Natural History Museum

176 of Utah.

177

178 Description of the new material: UMNH.IP.6162 is a completely articulated individual preserved

179 as a lateral compression (Fig. 2), with a maximum main body length of $50 \mathrm{~mm}$ (sag.; tailspine

180 excluded). Body consists of head region covered by head shield, 11-segmented trunk, and

181 tailspine. Head shield longer (antero-posteriorly) than high (dorso-ventrally) - its dorsal margin

182 almost flat posteriorly, strongly sloped down anteriorly - with straight posterior margin (Fig. 3)

183 [Figure 3 nearby]; no dorsal ecdysial sutures or differentiated axis (Figs. 2, 3, 4A). Trunk

184 segments $1-10$ covered dorsally by broadly overlapping tergites of subequal length (sag.), and

185 bearing ventral appendages (Figs. 2A, 3A-C); terminal (11 $11^{\text {th }}$ ) trunk segment cylindrical and 
186 bearing caudal flaps and tailspine (Figs. 2, 3, 4E, F). Tailspine spiniform, exceeding main body

187 length (sag.), apparently uniarticulated, and with broad rounded base telescoped within posterior

188 half of $11^{\text {th }}$ trunk segment; single visible articulation at boundary between first and second thirds

189 of tailspine, associated with short dorsal spine-like extension of proximal part (Figs. 3, 4F).

190 Ventral structures preserved in UMNH.IP.6162 include one lateral eye (at least), a pair of

191 antennae, the remains of post-antennal appendages, and a pair of caudal flaps (Fig. 2-4). Large

192 ovoid patch of carbonaceous material on UMNH.IP.6162a interpreted as an eye; it is located

193 under anterior third of headshield, close to its ventral margin, and partly overlaps another ovoid

194 structure still largely covered by cuticle that likely represents the corresponding left eye (Fig.

195 4A-C). [Figure 4 nearby] Antennae flagelliform, elongate, and flexible (Figs. 2, 3, 4A); one

antenna inserts on ventral surface of head a short distance below right eye, and projects antero-

197

ventrally under head shield, then antero-dorsally, and finally abruptly bends dorsally; other

antenna gently curves ventrally, then abruptly bends dorsally distally (Fig. 4A). First post-

199

antennal appendages consist of elongate endopods only; they are equipped with strong, medially-

directed, spiniform endites, and prominent terminal claws (one each), and comprise at least five

201

podomeres (claw included; Fig. 4A, D). Following tergites associated with the appendages of

one side only. Second post-antennal appendage represented by its exopod only; proximal

anatomy unclear, but exopod extends into long paddle-shaped lobe fringed with robust setae

distally (Fig. 3C-E, 4E); corresponding endopod most likely concealed by overlying exopod

and/or sediment. Last cephalic appendage and following ten trunk ones similar in preservation

and morphology to second post-antennal appendage, except for moderate decrease of exopod 
207 length beyond mid-trunk (Figs. 3, 4E). Terminal $\left(11^{\text {th }}\right)$ trunk segment bears pair of posteriorly

208 oriented caudal flaps that apparently insert under its posterior half, as suggested by gap between

209 them and exopod of preceding segment; caudal flaps resemble elongate trunk exopods with distal

210 lobes bearing robust marginal setae (Figs. 3, 4E). Discontinuous dark trace, likely made of

211 carbon film, runs along ventral margin of body and produces short projections within exopod

212 proximal parts (Fig. 3); this trace starts close to insertion sites of antennae and can be tentatively

213 followed posteriorly to base of tailspine (Fig. 3C). Whether these structures represent remains of

214 gut and digestive glands, circulatory system, decay fluids, or combination of two or more of

215 these elements is unclear.

216

217 Remarks: UMNH.IP.6162 ideally complements the holotype and previously only specimen of $E$.

218 brutoni, which is dorso-ventrally flattened and contains little appendicular data (Figs. 1, 2). The

219 new specimen confirms the presence of 10 trunk tergites with expanded pleurae in this taxon,

220 and also illustrates other features that are unique within the genus. We propose to regard the

221 presence of ventrally projecting lateral eyes, and robust setae on the exopods and caudal flaps as

222 additional diagnostic characters of E. brutoni (Fig. 5). [Figure 5 nearby] Stein, Church \&

223 Robison (2011, figs. 2, 3) interpreted several transverse marks on the proximal part of the

224 tailspine of the holotype of E. brutoni as putative articulations; only one joint associated with a

225 tiny dorsal spine can be observed in the new specimen, but the absence of other articulations

226 might be an artefact of preservation, for the segmentation of the antennae is not preserved either. 


\section{Discussion}

\section{Comparison between Emeraldella species}

232 The morphology of E. brutoni from the Wheeler Formation (Stein, Church \& Robison, 2011), as

233 informed by new specimen UMNH.IP.6162, shows close parallels with that of E. brocki from the

234 Burgess Shale (Bruton \& Whittington, 1983; Stein \& Selden, 2012). Both taxa share a similar

235 dorsal exoskeleton consisting of a semicircular head shield with acute genal angles, a series of

236 freely articulating trunk tergites of subequal length (sag.) with expanded pleurae, a cylindrical

237 terminal tergite, and a spiniform tailspine exceeding the length (sag.) of the main body (Figs. 1,

238 2, 5). Emeraldella species also possess a comparable appendage organization including: long

239 antennae; first post-antennal limbs solely composed of spine-bearing endopods; following limbs

240 with distal paddle-shaped exopodal lobes bearing marginal setae; and paired caudal flaps with

241 marginal setae that occupy a lateroventral position relative to the tailspine (Figs. 1D, 4E).

242 Both E. brocki and E. brutoni have been suggested to possess an anterior sclerite, also

243 referred to as 'rostral plate' or 'pre-hypostomal sclerite' (Stein, Church \& Robison, 2011; Stein

$244 \&$ Selden, 2012). However, tentative evidence for this sclerite has only been observed in a single

245 specimen for each species (see Stein \& Selden, 2012, fig. 4A; Stein, Church \& Robison, 2011,

246 fig. 2.1 and 2.2), while other well-preserved specimens of E. brocki that are exposed in dorsal or

247 ventral views do not show any indications of this structure. UMNH.IP.6162 does not show traces

248 of an anterior sclerite either, or any other additional structures associated with the head shield 
249 (Fig. 4A). What has been interpreted as a possible 'pre-hypostomal sclerite' in the holotype

250 seems in continuity with the rest of the headshield (i.e. no furrow; Stein, Church \& Robison,

2512011 , fig. 2.1), and therefore likely corresponds to the slightly deformed anteromedial part of this

252 sclerite (Fig. 1C). In the case of E. brocki (see Stein \& Selden, 2012, fig. 4A), we believe that the

253 putative anterior sclerite similarly represents a compression line on the anterior edge of the head

254 shield, which has been produced by the outline of the adjacent antennae and first post-antennal

255 limbs, rather than a discrete exoskeletal plate. Moreover, the anterior sclerite of Cambrian

256 euarthropods is usually clearly distinguished at the anterior edge of the head shield, and either

257 accommodated in a median notch (e.g. Ortega-Hernández, 2015) or articulated with a natant

258 hypostome (see Hou \& Bergström, 1997; Edgecombe \& Ramsköld, 1999). This is not observed

259 in any of the two Emeraldella species and accordingly, we consider that there is no conclusive

260 evidence supporting the presence of an anterior sclerite in this genus.

261 Stein, Church \& Robison (2011) noted that the main feature that distinguishes E. brutoni

262 from E. brocki is the presence of 10, rather than 11 trunk tergites with developed pleurae (Bruton

263 \& Whittington, 1983; Stein \& Selden, 2012). UMNH.IP.6162 reveals further differences between

264 the two species. E. brutoni features a set of lateral eyes (Fig. 4B, C), whereas ocular structures

265 are confidently absent in the type species given the abundance of well-preserved material

266 (Bruton \& Whittington, 1983; Stein \& Selden, 2012). The structures born by the appendages of

267 E. brutoni also appear more robust than those of E. brocki. For example, the $1^{\text {st }}$ post-antennal

268 endopod of E. brutoni are equipped with stout spines (Fig. 4C), rather than hair-like endites as in

269 E. brocki (Stein \& Selden, 2012). Likewise, the distal exopodal lobes and the caudal flaps bear 
270 closely-packed, lamella-like elements in E. brutoni (Fig. 4E), rather than delicate, widely-spaced

271 marginal setae in the Burgess Shale species (Stein \& Selden, 2012, figs. 4, 5, 7, 8, 10).

272 One of the most striking characteristics of E. brocki is the presence of extremely long

273 antennae that can bear in excess of 80 articles in some specimens (Bruton \& Whittington, 1983;

274 Stein \& Selden, 2012). The antennae of E. brutoni might have been just as long, but their

275 preservation in the two available specimens does not permit to estimate their full extent, or even

276 the number of articles composing their preserved parts (Figs. 1, 2, 3, 4A). Most endopods (except

277 for the $1^{\text {st }}$ post-antennal pair) of UMNH.IP.6162 are not observable, which might be due to them

278 being in a deeper topographic plane within the matrix or simply concealed by the exopods. If the

279 latter case is true, this would indicate a significant difference in endopod length between the two

280 species, as the endopods on the anterior half of the body of E. brocki extend well-beyond the

281 dorsal exoskeletal boundaries, and are much longer than the corresponding exopods (Stein \&

282 Selden, 2012, figs. 5, 6, 7). Lastly, some aspects of the anatomy of E. brutoni - such as the shape

283 of its hypostome, the morphology of its endopods (except for the $1^{\text {st }}$ post-antennal ones) and

284 proximal parts of its exopods, or the organisation of its sternites - remain unknown, while they

285 are well documented in E. brocki (see Stein \& Selden, 2012). Gaining access to such anatomical

286 details in the future might provide additional characters distinguishing the two species.

288 Origin of the caudal appendicular derivatives of Vicissicaudata

289 The affinities of Emeraldella within Artiopoda have become more or less stable in recent years,

290 thanks to the availability of exceptionally preserved material and broad-scale phylogenetic 
291 analyses of Cambrian euarthropods (Edgecombe \& Ramsköld, 1999; Cotton \& Braddy, 2004;

292 Stein \& Selden, 2012; Legg, Sutton \& Edgecombe, 2013; Ortega-Hernández, Legg \& Braddy,

293 2013; Lerosey-Aubril, Zhu \& Ortega-Hernández, 2017a; Aria \& Caron, 2017). These analyses

294 generally have recovered Emeraldella as forming a clade with aglaspidids, cheloniellids, and

295 Sidneyia. This clade Vicissicaudata (Ortega-Hernández, Legg \& Braddy, 2013), now regarded as

296 a superclass (Lerosey-Aubril, Zhu \& Ortega-Hernández, 2017a), is defined by a trunk with well-

297 developed tergopleurae, except for at least one cylindrical terminal segment that also bears

298 paired structures regarded by most workers as appendicular derivatives (e.g. Raymond, 1920;

299 Hou \& Bergstrom, 1997; Van Roy, 2006a; Stein \& Selden, 2012; Ortega-Hernández, Legg \&

300 Braddy, 2013). However, the morphology of the latter structures and their connection to the rest

301 of the body vary greatly within the Vicissicaudata, and it is still unclear how each type has

302 evolved from normal trunk appendages.

303 Aglaspidids are characterized by the presence of paired sclerotized plates covering ventrally

304 the posteriormost two or three trunk tergites and the base of the tailspine (Hesselbo, 1992; Van

305 Roy, 2006a; Ortega-Hernández, Legg \& Braddy, 2013). These so-called 'post-ventral plates'

306 have been repeatedly regarded as homologous to the caudal flaps of Emeraldella (Wills et al.,

307 1998; Cotton \& Braddy, 2004; Van Roy, 2006a), despite substantial differences in shape,

308 structure, and position between them. For a long time, the hypothesis of an appendicular origin

309 of aglaspidid post-ventral plates heavily relied on the fact that these structures were paired (e.g.

310 Cotton \& Braddy, 2004; Van Roy, 2006a), but recent studies have shed light on the origin of

311 appendicular derivatives in this group. Indeed, Lerosey-Aubril et al. (2017b) showed that the 
312 broad-based tailspine characterizing many aglaspidids has likely evolved through the fusion of a

313 cylindrical terminal segment and a needle-like telson. More importantly, the aglaspidid

314 Glypharthrus trispinicaudatus demonstrates that such a freely articulated terminal segment also

315 includes a pair of non-articulated caudal rami projecting from its posterior margin (Lerosey-

316 Aubril, Zhu \& Ortega-Hernández, 2017a), a condition closely reminiscent of Emeraldella and

317 cheloniellids. It seems now likely that the 'normal' appendages of the terminal segment of the

318 vicissicaudatan ancestor initially evolved into caudal rami in the aglaspidid or aglaspidid +

319 cheloniellid lineage. However, it remains unclear whether these caudal rami have later evolved

320 into the post-ventral plates of more derived aglaspidids, or if the fusion of the pre-terminal

321 segment and the telson has resulted in their loss; the latter scenario would imply that the post-

322 ventral plates have evolved independently, possibly from a different body segment altogether

323 (Lerosey-Aubril, Zhu \& Ortega-Hernández, 2017a).

324 In cheloniellids, the terminal cylindrical trunk tergite bears a pair of rami, which can be short

325 and articulated (Van Roy, 2006b) or long and unsegmented (Stürmer \& Bergström, 1978). Even

326 if one accepts an appendicular origin for these structures, their derived morphology provides no

327 clue as to how they have evolved from conventional trunk appendages, and their dorsal insertion

328 (Van Roy, 2006b) suggests evolutionary transformations unique to the cheloniellid lineage.

329 Lastly, the exact nature of the uropods of Sidneyia is unclear. They are large, unsegmented

330 structures (e.g. Bruton, 1981; Zacaï, Vannier \& Lerosey-Aubril, 2016), which appear totally

331 fused to the telson (Lerosey-Aubril et al., 2017b). How exactly they might have evolved from

332 regular trunk appendages remains unknown. 
Of all known vicissicaudates, Emeraldella shows the least derived condition with regard to

334 the structures born by the cylindrical terminal trunk segment. Its caudal flaps provide a valuable

335 reference point for understanding the origin of this diagnostic feature of the superclass. Most

336 authors have considered an appendicular origin for the caudal flaps in E. brocki (e.g. Raymond,

337 1920; Hou \& Bergstrom, 1997; Van Roy, 2006a; Stein \& Selden, 2012; Ortega-Hernández, Legg

$338 \&$ Braddy, 2013), with the exception of Bruton \& Whittington (1983), who regarded them as a

339 single bilobate ventral plate. The well-preserved caudal flaps of E. brutoni (Figs. 1D, 4E) show a

340 remarkable degree of similarity with the distal parts of the trunk exopods (Stein \& Selden, 2012),

341 including their lobate shape and presence of marginal setae. Interestingly, the main difference

342 between the caudal flaps of the two Emeraldella species is also the main difference expressed by

343 their trunk exopods, namely that both structures are fringed with delicate setae in E. brocki,

344 whereas they bear robust, lamella-like ones in E. brutoni. Stein \& Selden (2012) noted that the

345 setae of a caudal flap are 'shorter, more robust, and more widely spaced than those of the

346 exopod' in E. brocki, but this does not seem to be the case in E. brutoni (Fig. 4E). The same

347 authors reconstructed these flaps as bipartite, with short triangular proximal parts and elongate

348 distal lobes (Stein \& Selden, 2012, fig. 11A), but the morphology of the proximal region is

349 mostly speculative, as acknowledged in their text (p. 16); unfortunately, UMNH.IP.6162 does

350 not provide more information in this regard.

351 Based on these observations, we hypothesize that the evolution of the caudal flaps in

352 Emeraldella likely resulted from a series of transformations of a typical biramous trunk

353 appendage. These changes involved the loss of the endopod, the possible reduction or loss of the 
354 proximal exopod shaft, the elongation and narrowing of the exopod distal lobe, the re-orientation

355 of this exopod from a ventral to a posterior direction, and possibly the migration of its insertion

356 site on the body from the central region to the posterior region of the terminal segment. At least

357 some of these transformations (re-orientation, posterior migration of insertion site) might have

358 accompanied the evolution of the shape of the terminal cylindrical segment. In this evolutionary

359 scenario, the caudal structures of other vicissicaudates, and particularly those of aglaspidids and

360 cheloniellids, would fundamentally represent heavily modified exopods of the pre-terminal

361 segment, which may find some support in the fact that none of them show evidence of biramy.

362 The new specimen of E. brutoni also points to another appendicular differentiation that

363 could potentially further characterize vicissicaudates. UMNH.IP.6162 clearly shows that the $1^{\text {st }}$

364 post-antennal appendage lacks an exopod in this species, demonstrating at the same time that the

365 similar condition observed in E. brocki is legitimate, rather than a preservation artefact (Bruton

$366 \&$ Whittington, 1983; contra Stein \& Selden, 2012). Other vicissicaudates, such as Sidneyia

367 (Bruton, 1981; Stein, 2013) and Cheloniellon calmani Broili, 1932 (see also Stürmer \&

368 Bergström, 1978), are also known to lack exopods on at least the first post-antennal limb pair.

369 No exopods whatsoever are known in the only known specimens of Aglaspis (Briggs et al.,

370 1979) and Flobertia (Hesselbo, 1992) with appendicular remains (one specimen per taxon), but

371 this might be due to incomplete preservation. Indeed, exopods are clearly expressed in the

372 aglaspidid Kankhaspis from Siberia (Repina \& Okuneva, 1969), although a comprehensive

373 restudy of the material would be needed to determine whether all post-antennal cephalic

374 appendages are biramous. Otherwise, appendicular data are missing for most aglaspidids 
375 (Hesselbo, 1992; Van Roy, 2006a; Fortey \& Rushton, 2009; Ortega-Hernández et al., 2010;

376 Ortega-Hernández, Legg \& Braddy, 2013; Ortega-Hernández, Van Roy \& Lerosey-Aubril, 2016;

377 Lerosey-Aubril et al., 2013a; Lerosey-Aubril et al., 2013b; Lerosey-Aubril et al., 2017a;

378 Lerosey-Aubril et al., 2017b; Siveter et al., 2018) and cheloniellids (e.g. Chlupác, 1988; Dunlop,

379 2002), thus preventing a more complete assessment of how common the presence of a uniramous

380 first post-antennal appendage is in vicissicaudates. Yet, particular attention should be given to

381 this morphological trait in the future, for it might lead to a more accurate concept of

382 Vicissicaudata.

383

384 Conclusions

385 The remarkable Miaolingian biotas of Utah have proved quite diverse with time, but most of

386 their components remain poorly known due to the scarcity of available material. Each new soft-

387 bodied fossil recovered from these beds can significantly improve our understanding of the

388 anatomy or palaeocology of these taxa, and therefore refine our depiction of these ancient biotas.

389 This is illustrated here with the description of a new specimen of E. brutoni, which allows the

390 detailed description of the appendicular anatomy of this species for the first time. The appendage

391 organization of E. brutoni suggest an exopodal origin for the caudal appendicular derivatives in

392 the diverse clade Vicissicaudata. Its description also offers an opportunity to discuss the

393 differentiation of the first post-antennal appendage into a uniramous structure (endopod) as a

394 potentially diagnostic character of the superclass. 
Further investigations on the clade Vicissicaudata might benefit from considering possibly

396

397

398

399

400

401

402

403

404

405

406

407

408

409

410

411

412

413

414

415

related taxa, such as Molaria spinifera Walcott, 1912. Several studies have already argued for a

possible sister-group relationship between Emeraldella and Molaria based on their tergite

morphology, and presence of a multiarticulated tailspine (Whittington 1981; Stein, Church \&

Robison, 2011; Legg, Sutton \& Edgecombe, 2013). Molaria also shares with vicissicaudates the

presence of a terminal cylindrical segment devoid of walking legs. This segment has been

described as completely limbless (Whittington, 1981), but it bears a pair of short spines flanking

the tailspine laterally, which might represent heavily modified appendages. Only a proper re-

study of this taxon would permit to test this assumption.

\section{Acknowledgements}

Brock Sisson found the new specimen of E. brutoni described in this study. Carolyn Levitt-

Bussian and Randal B. Irmis facilitated its study, and kindly assisted us during our visits to the

Natural History Museum of Utah. The Bureau of Land Management, particularly Scott E. Foss

and Greg McDonald, deposited the specimen in the museum and provided curation assistance.

Martin Stein took the pictures of the holotype specimen and allowed us to use them in Figure 1.

A. Daley, G. Edgecombe, and an anonymous colleague provided us with detailed reviews that greatly improved our manuscript. We would like to express our sincere gratitude to all of these people for their invaluable help before and during the course of our study. 


\section{References}

417 Aria, C. and Caron, J.-B., 2017. Mandibulate convergence in an armoured Cambrian stem

$418 \quad$ chelicerate. BMC Evolutionary Biology, 17(1), p.261.

419 Brett, C.E., Allison, P.A., Desantis, M.K., Liddell, W.D. and Kramer, A. 2009. Sequence

420 stratigraphy, cyclic facies, and lagerstätten in the Middle Cambrian Wheeler and Marjum

421 formations, Great Basin, Utah. Palaeogeography, Palaeoclimatology, Palaeoecology,

422 277, pp.9-33.

423

424

425

426

427

428

431

Broili, F. 1932. Ein neuer Crustacee aus dem rheinischen Unterdevon. Sitzungsberichte Bayerische Akademie der Wissenschaften, 1932, p.27-38.

Briggs, D.E.G. and Robison, R.A. 1984. Exceptionally preserved nontrilobite arthropods and Anomalocaris from the Middle Cambrian of Utah. The University of Kansas Paleontological Contributions, 111, pp.1-24.

Briggs, D.E.G., Bruton, D.L. and Whittington, H.B. 1979. Appendages of the arthropod Aglaspis spinifer (Upper Cambrian, Wisconsin) and their significance. Palaeontology, 22, pp.167180.

Briggs, D.E.G., Lieberman, B.S., Hendricks, J.R., Halgedahl, S.L. and Jarrard, R.D. 2008. Middle Cambrian arthropods from Utah. Journal of Paleontology, 82, pp.238-254.

Brooks, H.K. and Caster, K.E. 1956. Pseudoarctolepis sharpi, n. gen., n. sp. (Phyllocarida), from the Wheeler Shale (Middle Cambrian) of Utah. Journal of Paleontology, 31, pp.9-14. 
435 Bruton, D. L., 1981. The arthropod Sidneyia inexpectans, Middle Cambrian, Burgess Shale,

436 British Columbia. Philosophical Transactions of the Royal Society B, Biological Sciences, 295, pp.619-653.

Bruton, D.L. and Whittington, H.B., 1983. Emeraldella and Leanchoilia, two arthropods from the Burgess Shale, Middle Cambrian, British Columbia. Philosophical Transactions of the Royal Society of London. B, Biological Sciences, 300(1102), pp.553-582.

Butler, A.D., Cunningham, J.A., Budd, G.E. and Donoghue, P.C.J., 2015. Experimental taphonomy of Artemia reveals the role of endogenous microbes in mediating decay and fossilization. Proceedings of the Royal Society B: Biological Sciences, 282(1808), p.20150476.

Chlupác, I., 1988. The enigmatic arthropod Duslia from the Ordovician of Czechoslovakia. Palaeontology, 31(Part 3), pp.611-620.

Conway Morris, S.C. 1985. Cambrian Lagerstätten: their distribution and significance. Philosophical Transactions of the Royal Society of London, B, 311, pp.49-65. of some Cambrian biotas. Journal of Paleontology, 56, pp.116-122. 117, pp.1-22. 
454 Conway Morris, S. and Robison, R.A. 1988. More soft-bodied animals and algae from the

455 Middle Cambrian of Utah and British Columbia. The University of Kansas

$456 \quad$ Paleontological Contributions, 122, pp.1-48.

457 Conway Morris, S., Selden, P.A., Gunther, G., Jamison, P.G., \& Robison, R.A. 2015. New

458 records of Burgess Shale-type taxa from the middle Cambrian of Utah. Journal of

459 Paleontology, 89, pp.411-423.

460 Cotton, T.J. and Braddy, S.J., 2004. The phylogeny of arachnomorph arthropods and the origin

461 of the Chelicerata. Earth and Environmental Science Transactions of The Royal Society of

462 Edinburgh, 94(3), pp.169-193.

463 Dunlop, J.A., 2002. Arthropods from the Lower Devonian Severnaya Zemlya Formation of

464 October Revolution Island (Russia). Geodiversitas, 24(2), pp.349-379.

465 Edgecombe, G.D. and Ramsköld, L., 1999. Relationships of Cambrian Arachnata and the

466 systematic position of Trilobita. Journal of Paleontology, 73(2), pp.263-287.

467 Fortey, R.A. and Rushton, A.W., 2009. The Ordovician Aglaspidid Arthropod Tremaglaspis

468 Reconsidered. Memoirs of the Association of Australasian Palaeontologists, (37), p.17.

469 Foster, J.R. and Gaines, R.R. 2016. Taphonomy and Paleoecology of the "Middle" Cambrian

470 (Series 3) Formations in Utah's West Desert: recent finds and new data. 291-336. In

471 Comer, J.B., Inkenbrandt, P.C., Krahulec, K.A. and Pinnell, M.L. (eds). Resources and

472 Geology of Utah's West Desert. Utah Geological Association, Publication, 45, 377 pp.

473 Gaines, R.R. 2014. Burgess Shale-type preservation and its distribution in space and time. The 
475 Gunther, L.F. and Gunther, V.G. 1981. Some Middle Cambrian fossils of Utah. Brigham Young $476 \quad$ University Geology Studies, 28, pp.1-81.

477 Halgedahl, S., Jarard, R., Brett, C.E., and Allison, P.A. 2009. Geophysical and geological

478 signatures of relative sea level change in the upper Wheeler Formation, Drum Mountains,

479 West-central Utah: a perspective into exceptional preservation of fossils.

480 Palaeogeography, Palaeoclimatology, Palaeoecology, 277, pp.34-56.

481 Hesselbo, S. P. 1992. Aglaspidida (Arthropoda) from the Upper Cambrian of Wisconsin. Journal 482 of Paleontology, 66, pp.885-923.

483 Hou, X., and Bergstrom, J. 1997. Arthropods of the lower Cambrian Chengjiang fauna, 484 Southwest China. Fossils \& Strata 45: 1-116.

485 Lankester, E. R. 1904. The structure and classification of Arthropoda. Quarterly Journal of $486 \quad$ Microscopical Science 47: 523-582.

487 Legg, D.A., Sutton, M.D. and Edgecombe, G.D., 2013. Arthropod fossil data increase congruence of morphological and molecular phylogenies. Nature Communications, 4 , p. 2485 .

Lerosey-Aubril, R. 2015. Notchia weugi gen. et sp. nov., a new short-headed arthropod from the Weeks Formation Konservat-Lagerstätte (Cambrian; Utah). Geological Magazine, 152, pp.351-357.

Lerosey-Aubril R. and Skabelund J. 2018. Messorocaris, a new sanctacaridid-like arthropod pp.181-186. 
496 Lerosey-Aubril, R., Hegna, T.A., Kier, C., Bonino, E., Habersetzer, J. and Carré, M. 2012.

497 Controls on gut phosphatisation: the trilobites from the Weeks Formation Lagerstätte

498 (Cambrian; Utah). PLoS One, 7, e32934. doi://10.1371/journal.pone.0032934

499 Lerosey-Aubril, R., Ortega-Hernández, J., Kier, C. and Bonino, E., 2013a. Occurrence of the

$500 \quad$ Ordovician-type aglaspidid Tremaglaspis in the Cambrian Weeks formation (Utah, USA).

$501 \quad$ Geological Magazine, 150, pp.945-951.

502 Lerosey-Aubril, R., Ortega-Hernández, J. and Zhu, X., 2013b. The first aglaspidid sensu stricto

503 from the Cambrian of China (Sandu Formation, Guangxi). Geological Magazine, 150(3),

$504 \quad$ pp.565-571.

505 Lerosey-Aubril, R., Zhu, X. and Ortega-Hernández, J., 2017a. The Vicissicaudata revisited-

506 insights from a new aglaspidid arthropod with caudal appendages from the Furongian of

507 China. Scientific Reports, 7(1), p.11117.

508 Lerosey-Aubril, R., Paterson, J. R., Gibb, S. and Chatterton, B. D. E. 2017b. Exceptionally-

509 preserved late Cambrian fossils from the McKay Group (British Columbia, Canada) and

510 the evolution of tagmosis in aglaspidid arthropods. Gondwana Research, 42, pp.264-279.

511 Lerosey-Aubril, R., Gaines, R.R., Hegna, T.A., Ortega-Hernández, J., Van Roy, P., Kier, C. and

512 Bonino, E. 2018. The Weeks Formation Konservat-Lagerstätte and the evolutionary

513 transition of Cambrian marine life. Journal of the Geological Society, 175, pp.705-715.

514 Miller, J.F., Evans, K.R. and Dattilo, B.F. 2012. The Great American Carbonate Bank in the

515 miogeocline of western central Utah: tectonic influences on sedimentation. In Derby, J.R.,

516 Fritz, R., Longacre, S.A., Morgan, M. \& Sternbach, C. (eds) The Great American 

pp.769-854.

520

521

522

523

524

525

526

527

528

529

530

531

532

533

534

535

Ortega-Hernández, J., Braddy, S.J., Jago, J.B. and Baillie, P.W., 2010. A new aglaspidid arthropod from the Upper Cambrian of Tasmania. Palaeontology, 53(5), pp.1065-1076.

Ortega-Hernández, J., Legg, D.A. and Braddy, S.J., 2013. The phylogeny of aglaspidid arthropods and the internal relationships within Artiopoda. Cladistics, 29(1), pp.15-45.

Ortega-Hernández, J., Lerosey-Aubril, R., Kier, C. and Bonino, E. 2015. A rare non-trilobite artiopodan from the Guzhangian (Cambrian Series 3) Weeks Formation KonservatLagerstätte in Utah, USA. Palaeontology, 58, pp.265-276.

Ortega-Hernández, J., Van Roy, P. and Lerosey-Aubril, R., 2016. A new aglaspidid euarthropod with a six-segmented trunk from the Lower Ordovician Fezouata Konservat-Lagerstätte, Morocco. Geological Magazine, 153(3), pp.524-536.

Raymond, P. E. 1920. Phylogeny of the Arthropoda with especial reference to the trilobites. American Naturalist, 54, pp.398-413.

Rees, M.N. 1986. A fault-controlled trough through a carbonate platform: the Middle Cambrian House Range embayment. Geological Society of America Bulletin, 97, pp.1054-1069.

Rigby, J.K. 1969. A new Middle Cambrian hexactinellid sponge from western Utah. Journal of Paleontology, 43, pp.125-128. 
536 Rigby, J.K. 1978. Porifera of the Middle Cambrian Wheeler Shale, from the Wheeler

537

538

539

540

541

542

543

544

545

546

547

548

549

550

551

552

553

554

555

556

Amphitheater, House Range, in Western Utah. Journal of Paleontology, 52, pp.1325-

1345.

Rigby, J.K. 1983. Sponges of the Middle Cambrian Marjum Limestone from the House Range and Drum Mountains of western Millard County, Utah. Journal of Paleontology, 57, pp. $240-270$.

Rigby, J.K., \& Gutschick, R.C. 1976. Two new Lower Paleozoic hexactinellid sponges from Utah and Oklahoma. Journal of Paleontology, 50, pp.79-85.

Robison, R.A. 1984. New occurrences of the unusual trilobite Naraoia from the Cambrian of Idaho and Utah. University of Kansas Paleontological Contributions, 112, pp.1-8.

Robison, R.A. 1985. Affinities of Aysheaia (Onychophora), with description of a new Cambrian species. Journal of Paleontology, 59, pp.226-235.

Robison, R.A. 1990. Earliest-known uniramous arthropod. Nature, 343, pp.163-164.

Robison, R.A. 1991. Middle Cambrian biotic diversity: examples from four Utah Lagerstätten. 77-98. In Simonetta, A. and Conway Morris, S. (eds). The Early Evolution of Metazoa and the Significance of Problematic Taxa. Cambridge University Press, Cambridge, U.K.

Robison, R.A. and Richards, B.C. 1981. Larger bivalve arthropods from the Middle Cambrian of Utah. The University of Kansas Paleontological Contributions, 106, pp.1-28.

Robison, R.A., Babcock, L.E. and Gunther, V.G. 2015. Exceptional Cambrian fossils from Utah: a window into the age of trilobites. Utah Geological Survey, Salt Lake City, Miscellaneous Publication, 15-1, pp. 1-97. 
557 Siveter, D.J., Fortey, R.A., Zhu, X. and Zhou, Z., 2018. A three-dimensionally preserved

558 aglaspidid euarthropod with a calcitic cuticle from the Ordovician of China. Geological

559 Magazine, 155(7), pp.1427-1441.

560 Stein, M., 2013. Cephalic and appendage morphology of the Cambrian arthropod Sidneyia

561 inexpectans. Zoologischer Anzeiger-A Journal of Comparative Zoology, 253(2), pp.164-

$562 \quad 178$.

563 Stein, M., Church, S.B. and Robison, R.A., 2011. A new Cambrian arthropod, Emeraldella brutoni, from Utah. Paleontological Contributions, 2011(3), pp.1-10.

565

566

567

568

569

570

571

572

573

574

575

576

577

Stein, M. and Selden, P.A., 2012. A restudy of the Burgess Shale (Cambrian) arthropod Emeraldella brocki and reassessment of its affinities. Journal of Systematic Palaeontology, 10(2), pp.361-383.

Stürmer, W. and Bergström, J. 1978. The arthropod Cheloniellon from the Devonian Hunsrück shale. Paläontologische Zeitschrift, 52, pp.57-81.

Van Roy, P., 2006a. An aglaspidid arthropod from the Upper Ordovician of Morocco with remarks on the affinities and limitations of Aglaspidida. Earth and Environmental Science Transactions of The Royal Society of Edinburgh, 96(4), pp.327-350.

Van Roy, P., 2006b. Non-Trilobite Arthropods from the Ordovician of Morocco. Ph.D. thesis, Ghent University.

Walcott, C. D. 1912. Cambrian geology and ppaleontology II. Middle Cambrian Branchiopoda, Malacostraca, Trilobita and Merostomata. Smithsonian Miscellaneous Collections 57: $145-229$. 
578 Willoughby, R.H. and Robison, R.A. 1979. Medusoids from the Middle Cambrian of Utah.

$579 \quad$ Journal of Paleontology, 56, pp.494-500.

580 Wills, M.A., Briggs, D.E.G., Fortey, R.A., Wilkinson, M., Sneath, P.H.A. 1998. An arthropod

581 phylogeny based on fossil and recent taxa. In: Edgecombe, G.D. (Ed.), Arthropod Fossils

582 and Phylogeny. Columbia University Press, New York, pp. 33-105.

583 Whittington, H. B. 1981. Rare arthropods from the Burgess Shale, Middle Cambrian, British

584 Columbia. Philosophical Transactions of the Royal Society B, Biological Sciences, 292,

$585 \quad$ pp.329-357.

586 Zacaï, A., Vannier, J., Lerosey-Aubril, R., 2016. Reconstructing the diet of a 505-million year-

587 old arthropod: Sidneyia inexpectans from the Burgess Shale fauna. Arthropod Structure

588 and Development, 45, pp.200-220.

589

590

591 Figure 1. Holotype (KUMIP 321500) of Emeraldella brutoni from the Cambrian (Drumian)

592 Wheeler Formation in the Drum Mountains. Pictures were taken with the specimen immersed

593 in dilute ethanol under cross-polarized light (Credit: M. Stein). (A) General view of the

594 counterpart (mirrored). (B) General view of part. (C) Detail of anterior cephalic region of

595 counterpart. (D) Detail of caudal flaps of part. Abbreviations: an, antenna; ar, anterior region of

596 headshield; $c f$, caudal flap; $c s$, cylindrical terminal segment; $h s$, head shield; $m s$, marginal setae;

$597 T \mathrm{n}$, trunk tergite; $t s$, tailspine. 
599 Figure 2. New specimen of Emeraldella brutoni from the Cambrian (Drumian) Wheeler

600 Formation in the Drum Mountains. Pictures taken with the specimen dry under cross-

601 polarized light. (A) Part, UMNH.IP.6162a. (B) Counterpart, UMNH.IP.6162b (mirrored).

602 Abbreviations: an, antenna; $c f$, caudal flap; $c$ n, cephalic appendage; $c s$, cylindrical terminal

603 segment; $h s$, head shield; Tn, tergite; trn, trunk appendage; $t s$, tailspine.

604

605 Figure 3. New specimen of Emeraldella brutoni from the Cambrian (Drumian) Wheeler

606 Formation in the Drum Mountains. Pictures taken with the specimen dry (A, E) or immersed

607 in dilute ethanol (B, D) under cross-polarized light. (A, B) Part, UMNH.IP.6162a. (C) Composite

608 interpretative drawing, combining details of both part and counterpart. (D, E) Counterpart,

609 UMNH.IP.6162b (mirrored). Abbreviations: an, antenna; $c f$, caudal flap; $c$; cephalic appendage;

$610 c s$, cylindrical terminal segment; ey, eye; $h s$, head shield; $T$ n, tergite; trn, trunk appendage; $t s$,

611 tailspine.

612

613 Figure 4. New specimen of Emeraldella brutoni from the Cambrian (Drumian) Wheeler

614 Formation in the Drum Mountains. Pictures taken with the specimen dry (E, F) or immersed

615 in dilute ethanol (A, B, D) under cross-polarized light. (A, B, D) Detailed views of the cephalic

616 region (A), the eyes (B), and a first post-antennal appendage (D) in part (UMNH.IP.6162a). (C)

617 Interpretative drawing of B. (E, F) Detailed views of the posterior trunk exopods and caudal

618 flaps (E) and tailspine (F) in counterpart (UMNH.IP.6162b); note the articulation (arrowhead)

619 associated with a tiny spine dorsally. Abbreviations: an, antenna; as, articulation spine; $c f$, caudal 
620 flap; $c$, cephalic appendage; $e n$, endite; $e y$, eye; $h s$, head shield; $m s$, marginal setae; trn, trunk

621 appendage.

622

623 Figure 5. Morphological reconstruction of Emeraldella brutoni. (A) Lateral view. (B) Dorsal

624 view. (C) Ventral view. The morphology of the hypostome, sternites, tripartite exopod

625 organization, and all but the first set of endopods are tentatively extrapolated from the better-

626 known Emeraldella brocki from the Burgess Shale (see Stein \& Selden, 2012). The presence of

627 simple rather than tripartite endopod tips is generalized from the morphology of the well-

628 preserved first post-antennal appendages. 


\section{Figure 1}

Figure 1. Holotype (KUMIP 321500) of Emeraldella brutoni from the Cambrian (Drumian) Wheeler Formation in the Drum Mountains.

Pictures were taken with the specimen immersed in dilute ethanol under cross-polarized light (Credit: M. Stein). (A) General view of the counterpart (mirrored). (B) General view of part. (C) Detail of anterior cephalic region of counterpart. (D) Detail of caudal flaps of part. Abbreviations: an, antenna; ar, anterior region of headshield; cf, caudal flap; cs, cylindrical terminal segment; $h s$, head shield; $m s$, marginal setae; $T n$, trunk tergite; ts, tailspine. 

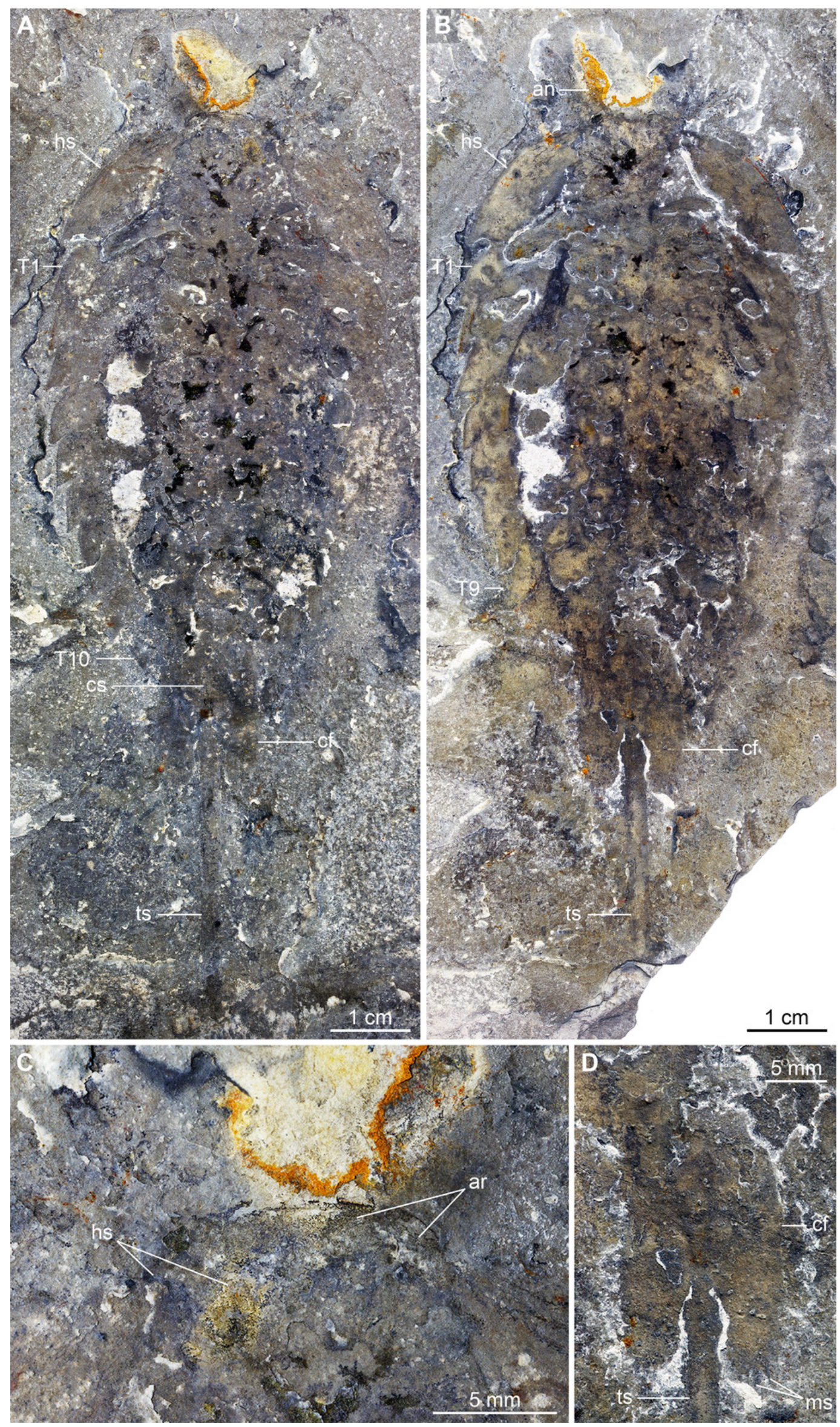

PeerJ reviewing PDF | (2019:07:39704:1:1:NEW 16 Sep 2019) 


\section{Figure 2}

Figure 2. New specimen of Emeraldella brutoni from the Cambrian (Drumian) Wheeler Formation in the Drum Mountains.

Pictures taken with the specimen dry under cross-polarized light. (A) Part, UMNH.IP.6162a.

(B) Counterpart, UMNH.IP.6162b (mirrored). Abbreviations: an, antenna; cf, caudal flap; cn, cephalic appendage; $c s$, cylindrical terminal segment; $h s$, head shield; $T n$, tergite; trn, trunk appendage; $t s$, tailspine.

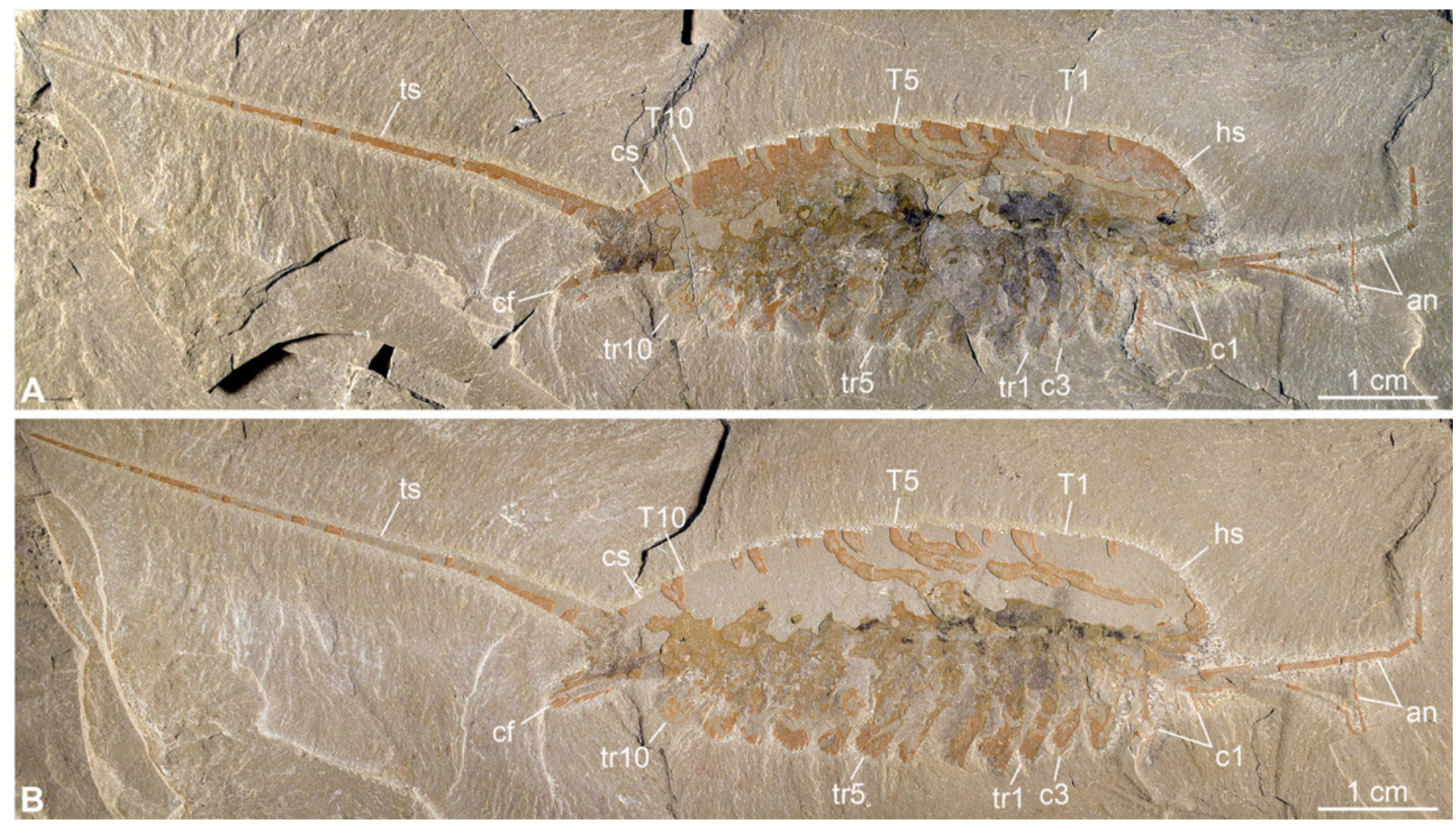




\section{Figure 3}

Figure 3. New specimen of Emeraldella brutoni from the Cambrian (Drumian) Wheeler Formation in the Drum Mountains.

Pictures taken with the specimen dry $(A, E)$ or immersed in dilute ethanol $(B, D)$ under crosspolarized light. (A, B) Part, UMNH.IP.6162a. (C) Composite interpretative drawing, combining details of both part and counterpart. (D, E) Counterpart, UMNH.IP.6162b (mirrored). Abbreviations: an, antenna; $c f$, caudal flap; cn; cephalic appendage; $c s$, cylindrical terminal segment; ey, eye; $h s$, head shield; $T n$, tergite; trn, trunk appendage; ts, tailspine. 

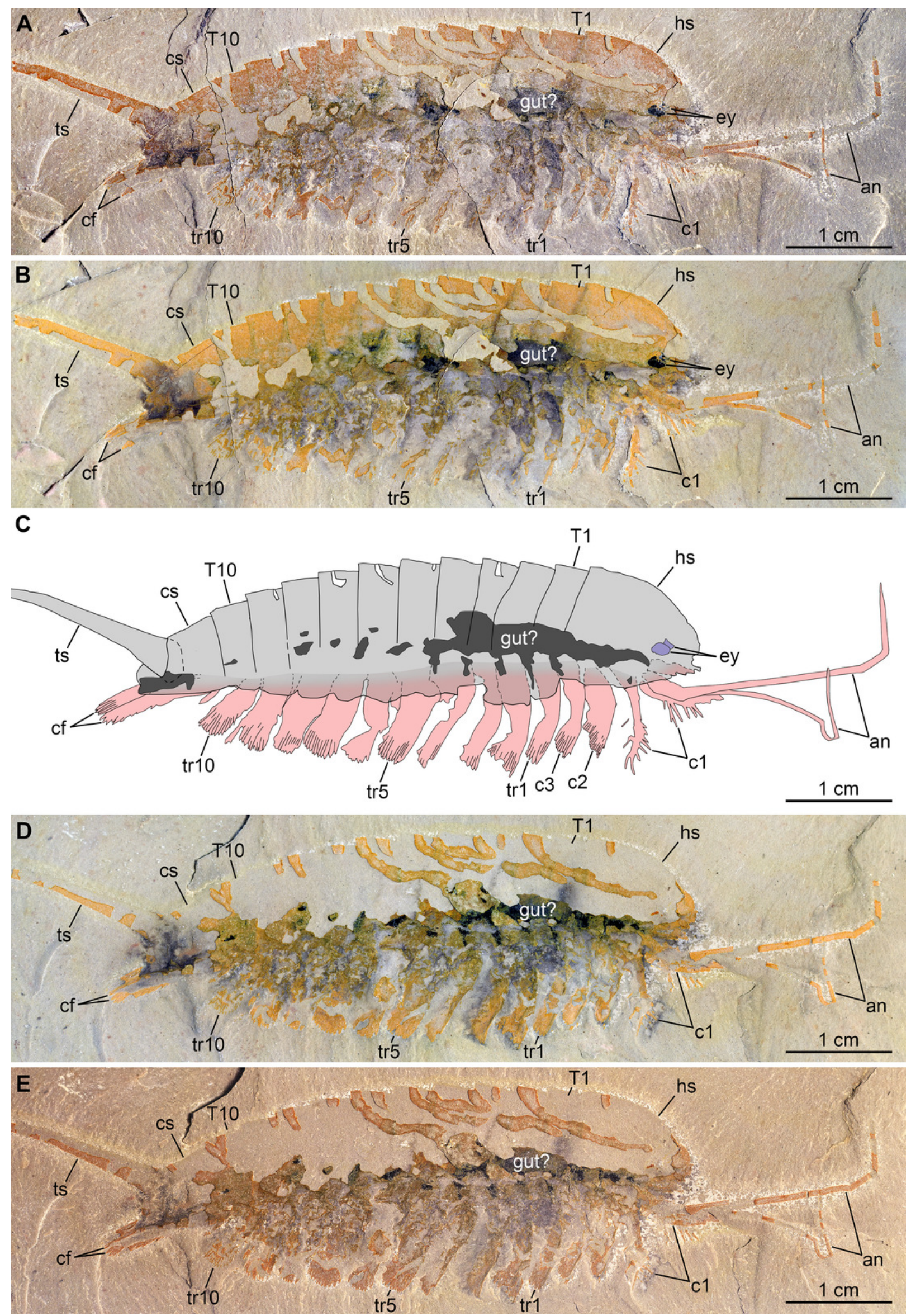

PeerJ reviewing PDF | (2019:07:39704:1:1:NEW 16 Sep 2019) 


\section{Figure 4}

Figure 4. New specimen of Emeraldella brutoni from the Cambrian (Drumian) Wheeler Formation in the Drum Mountains.

Pictures taken with the specimen dry $(E, F)$ or immersed in dilute ethanol $(A, B, D)$ under cross-polarized light. ( $A, B, D)$ Detailed views of the cephalic region (A), the eyes $(B)$, and a first post-antennal appendage (D) in part (UMNH.IP.6162a). (C) Interpretative drawing of B. $(E, F)$ Detailed views of the posterior trunk exopods and caudal flaps $(E)$ and tailspine $(F)$ in counterpart (UMNH.IP.6162b); note the articulation (arrowhead) associated with a tiny spine dorsally. Abbreviations: an, antenna; as, articulation spine; cf, caudal flap; $c n$, cephalic appendage; en, endite; ey, eye; $h s$, head shield; $m s$, marginal setae; trn, trunk appendage. 

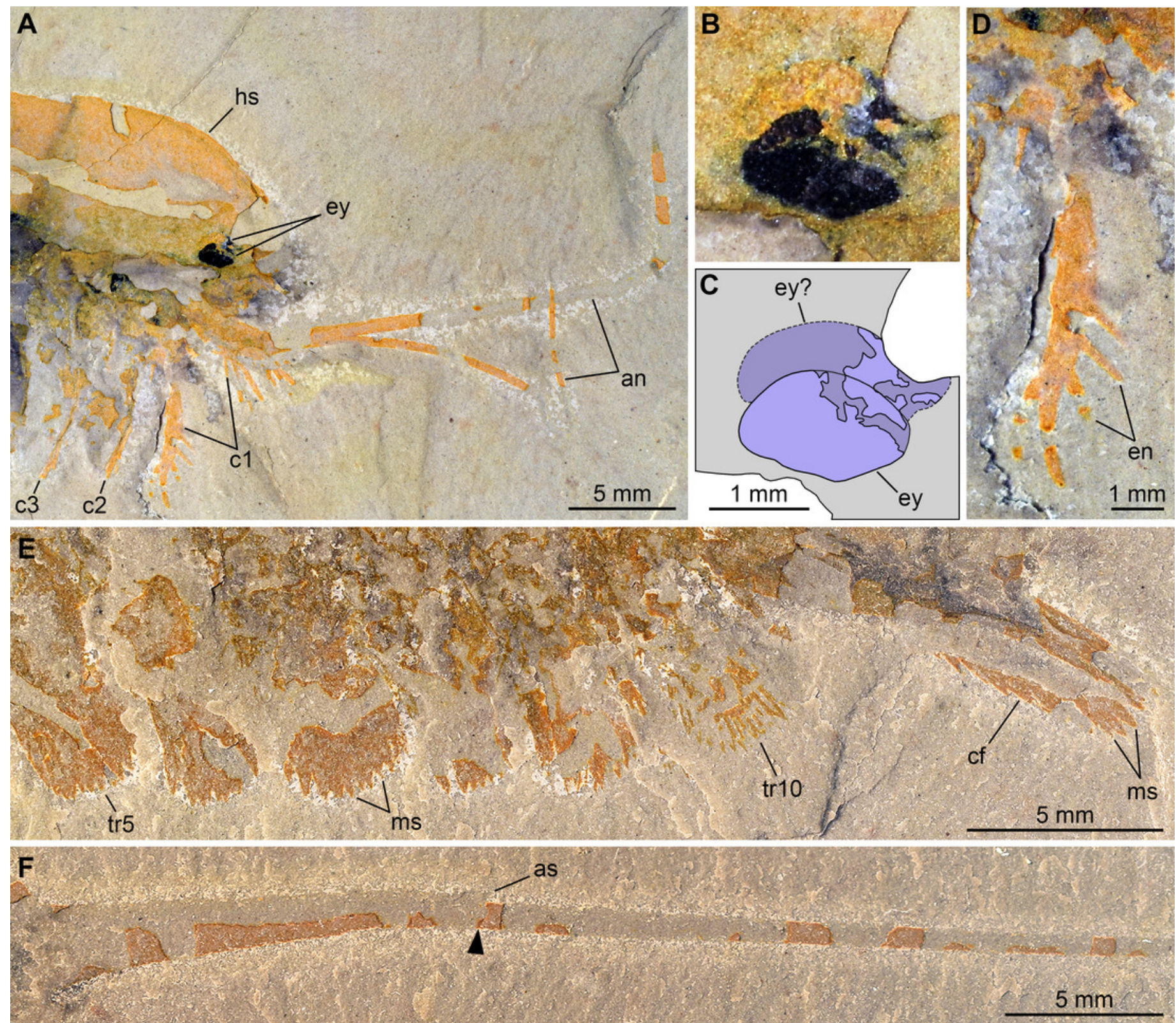


\section{Figure 5}

Figure 5. Morphological reconstruction of Emeraldella brutoni.

(A) Lateral view. (B) Dorsal view. (C) Ventral view. The morphology of the hypostome, sternites, tripartite exopod organization, and all but the first set of endopods are tentatively extrapolated from the better-known Emeraldella brocki from the Burgess Shale (see Stein \& Selden, 2012). The presence of simple rather than tripartite endopod tips is generalized from the morphology of the well-preserved first post-antennal appendages. 


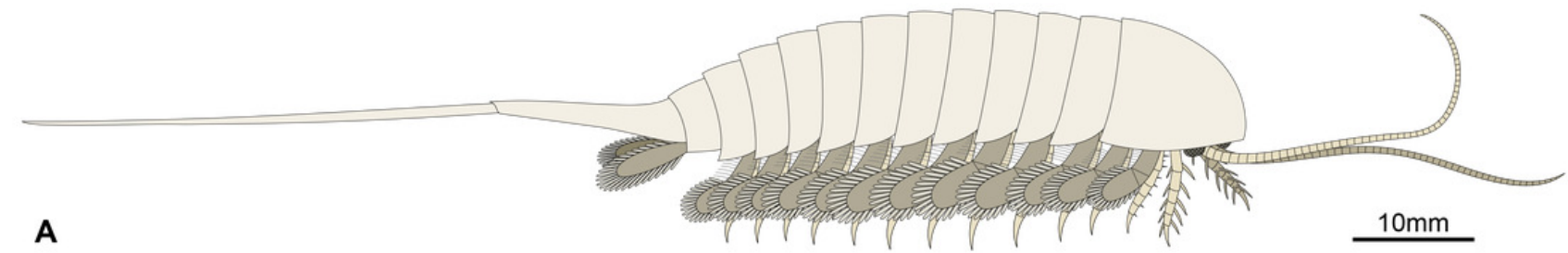

A

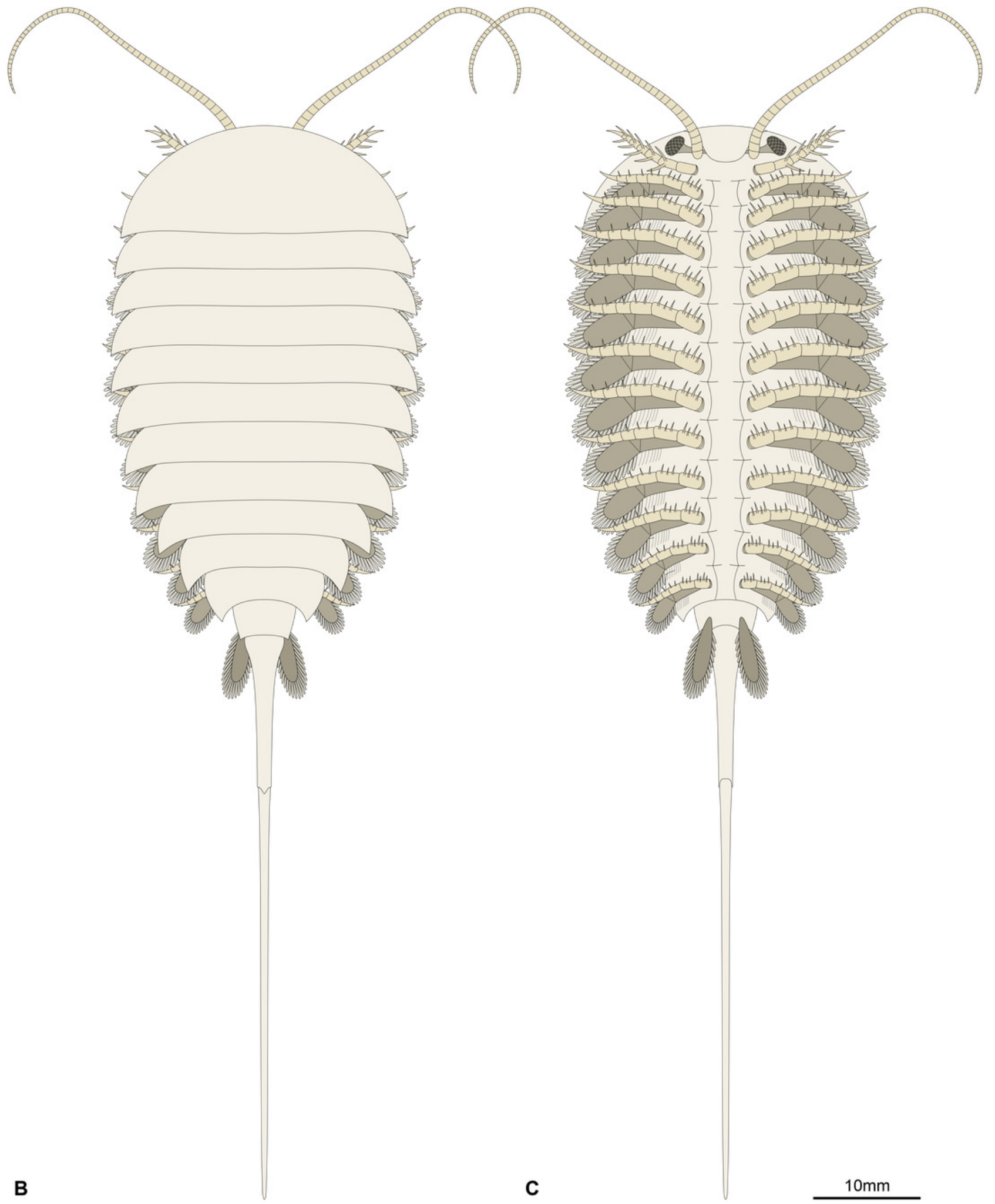

